\title{
Urban Metaphors in the Interaction of Child with Public Space
}

\author{
Hare Kılıçaslan \\ Karadeniz Technical University, Faculty of Architecture, Department of Architecture, \\ Trabzon, Turkey. ORCID: oooo-0oo2-6113-7962. Email: hkkilicaslan@gmail.com.
}

Received May 24, 2018; Revised May 27, 2018: Accepted on August 15, 2018; Published September 13, 2018.

\begin{abstract}
This research aims to reveal out the urban perceptions of 6-7-year old children and their sensual experiences about public spaces. The research comprised of 35 students in total (14 girls and 21 boys), studying at first grade in Bedri Rahmi Eyüboğlu Primary School in Ortahisar district of Trabzon province and was conducted in 2016-2017 academic year, spring term. The public spaces physically experienced by the children were identified through survey forms. Their urban perceptions were tried to be identified through the metaphors they created. Children filled in the blanks, "Trabzon is like ......... because ..........." to make statements, which were analyzed and interpreted through content analysis. The metaphors obtained were categorized based on their common characteristics. This research aims to reveal out the perceptions of the children on Trabzon with respect to the physically experienced public spaces and urban metaphors. The research findings are assumed to help the parents and teachers enhance the interaction of the children with the cities they live in and thus, improve the level of their spatial perception.
\end{abstract}

Keywords: Urban, Public Space, Perception, Child, Metaphor.

\section{Introduction}

Perception is individual's interpretation of an external phenomenon and making sense out of it. Experiences, personal background, perspective and mental style of an individual influence the quality of perception (İnceoğlu 2011: 128-131). So it could be said that the perceiving process varies from one person to another. Individuals obtain any information about themselves and their surrounding through perception. Perception occurs as a result of the interaction of the individual with the physical and social factors. Images are formed in one's brain through his/her perception of the external world, with the presence of sensual and visual impressions (Kilıçaslan, 2010). When all the senses are stimulated in a space, the sensation process comes out and physical perception takes place.

Every child interacts with his/her environment based on his/her personal characteristics and cultural differences. When people encounter spaces that are different in terms of function and form, their interaction with the environment varies too, which brings along experiences about the urban space. Varying spatial forms manifest themselves in public spaces, just like in all architectural creations. Public spaces, which make up the majority of the urban spaces, are the spaces where everybody in a city can benefit from and which belong to the public.

(c) AesthetixMS 2018. This Open Access article is published under a Creative Commons Attribution Non-Commercial 4.0 International License (http://creativecommons.org/licenses/by-nc/4.o/), which permits non-commercial re-use, distribution, and reproduction in any medium, provided the original work is properly cited. For citation use the DOI. For commercial re-use, please contact editor@rupkatha.com. 
The urban space is created through the interaction and relationships among the structures in the external space and the interaction between these structures and the other elements (İnceoğlu \& Aytuğ, 2009). On the other hand, public spaces are the places where the residents of the city communicate with each other and perform a variety of activities in their urban and public lives as a continuation of the internal spaces. Public space is defined as the space for common use where people living in the local area interact both with each other and with the surrounding built environment (Bayramoğlu, 2010).

The phrase "public space" was first introduced in 1962 by Jürgen Habermas in his book, "The Structural Formation of the Public Space: Researches on a Category of the Civilian Population (Strukturwandel der Öffentlichkeit)". Habermas defines the public space as "a living space covering the tools, processes and places in which the individuals talk and have a rational discussion about a matter that is of common concern to them and come to a common agreement about such matter as a result of this discussion" (Özbek, 2004).

Once the child gets out of the house, he/she encounters the urban space. For the child willing to explore and learn, the process environmental recognition and perception process starts as he/she starts to directly experience the space. By seeing new places, the children encounter new activity areas. As a result of their interaction with the space, the children observe, probably unconsciously and explore their surrounding through activities. They experience the space through physical features and stimulants. In this way, the children, just like the adults, evaluate the space sensually and can recognize the feelings evoked by such space. As the child interacts with the space, s/he reflects the acquainted experiences with his/her bodily sensations. The stance, attitude, position and pattern of movements the body reflects is related to the sensual mood encountered. It is proposed that revealing these moods encountered would contribute to determining children's levels of perceiving spaces.

Metaphor, as a form of vision and thought to understand the world, is used in the description of the perceptions regarding a certain phenomenon. Pallasmaa (2012) argues that it is the responsibility of architecture to create solid and experienced existential metaphors that materialize and structure our existence in the world. Morgan (1980) states that scientists often use metaphors while developing the theoretical frameworks and analytical tools they use in understanding the world. When metaphors, which help uncover how the concepts to be analyzed are perceived, are used for "describing", they define a situation, event or a phenomenon as it is" (Yıldırım \& Şimşek, 2013). As a way of expressing thoughts, metaphors are defined as "the statements structuring activities and thought" (Lakoff \& Johnson, 2003).

\section{Method}

This research aims to reveal out the levels of children in experiencing various public spaces and their perceptions of the city of Trabzon through the survey forms developed 
by the researcher. The phenomenological model among the qualitative research models, was used within the scope of the research. Phenomenology forms a suitable research base to examine the phenomena that are not totally foreign to us but which we cannot fully grasp, either. The phenomenological model was preferred to focus on phenomena that we are aware of but do not have an in-depth and detailed understanding (Yıldırım \& Şimşek, 2013).

The following questions were asked in this research:

1. What are the children's levels of experience regarding their perceptions of urban spaces?

2. What sort of sensual impressions are created by public spaces that children experience?

3. What are the metaphors stated by the children about Trabzon?

4. Under which conceptual categories can these metaphors be grouped?

\section{1. Study Group}

This research comprised of 35 students in total (14 girls and 21 boys), studying at first grade in Bedri Rahmi Eyüboğlu Primary School in Ortahisar district of Trabzon province and was conducted in 2016-2017 academic year, spring term. Distribution of children participating in the survey based on their demographic characteristics is presented in Table 1.

Table 1: Frequency and percentage distribution of the demographic characteristics of the children

\begin{tabular}{lll}
\hline Variable & f & \% \\
\hline Gender & & \\
\hline Female & 14 & 40 \\
\hline Male & 21 & 60 \\
\hline Educational background of the mother & & \\
\hline Primary school & $\mathbf{1}$ & $\mathbf{2 . 9}$ \\
\hline Secondary School & 4 & 11.4 \\
\hline High School & 8 & $\mathbf{2 2 . 9}$ \\
\hline Bachelor's Degree & 17 & 48.6 \\
\hline Master's degree & 5 & 14.3 \\
\hline Educational background of the father & & \\
\hline Primary school & 2 & 5.7 \\
\hline Secondary School & 2 & 5.7 \\
\hline High School & 11 & 31.4 \\
\hline Bachelor's Degree & 16 & 45.7 \\
\hline Master's degree & 4 & 11.4 \\
\hline Total & 35 & $\mathbf{1 0 0}$ \\
\hline
\end{tabular}




\section{2. Data Collection Tools}

The survey form developed by the researcher was used as data collection tool in the research. The first part of the survey consisted of the personal information about the children and questions about the places they visited in the city for dancing and spending their free times, their out of school activities, the public spaces they experienced and their sensual feelings about these spaces. In the second part of the survey, the children were asked to fill in the blanks of the statement "Trabzon is like because ." to produce a metaphor about the city.

\section{Findings}

The responses given to the closed-end questions were analyzed in the resolution and evaluation of survey data and their frequency and percentages were measured. The data obtained from the survey forms regarding the educational and social activities of the children outside school (such as courses, ateliers etc.) showed that, 31.4\% participated in various activities (sports/art activities) whereas $68.6 \%$ did not participate in any activity. Distribution of children based on their participation in out of school activities is presented in Table 2.

Table 2: Frequency and percentage distribution of the out-of-school activities of children

\begin{tabular}{lll}
\hline Out-of-school activities & f & \% \\
\hline Playing outside & $\mathbf{2 2}$ & 62.9 \\
\hline Spending time at home & 4 & 11.4 \\
\hline Going to the shopping mall & 4 & 11.4 \\
\hline Visiting relatives/friends & 3 & 8.6 \\
\hline Going to the market & $\mathbf{2}$ & 5.7 \\
\hline Total & 35 & $\mathbf{1 0 0}$ \\
\hline
\end{tabular}

Out-of-school activities that are presented in Table 2 were examined and it was observed that the majority of the children (62.9\%) preferred playing outside. Accordingly, it can be said that, the children prefer to spend the majority of their time playing outside.

Playing street games is the first activity that comes to mind when we talk about outside activities. Many games played either individually or in groups are influential in the personal development and socialization of the child. On the other hand, the children can engage in various sports, arts and cultural activities in urban public spaces. In this respect, it was intended to identify the urban spaces experienced by the children. The urban space-related experiences of the children participating in the research were evaluated based on various types of public spaces and presented in Table 3. 
Table 3: Frequency and percentage distribution of the public space experiences of children

\begin{tabular}{llll}
\hline Urban Spaces & Experience & f & \% \\
\hline \multirow{2}{*}{ Shopping Mall } & Yes & 34 & 97.1 \\
\cline { 2 - 4 } & No & 1 & 2.9 \\
\hline \multirow{2}{*}{ City Hall } & Yes & 9 & 25.7 \\
\cline { 2 - 4 } & No & 26 & 74.3 \\
\hline \multirow{2}{*}{ Mosque } & Yes & 31 & 88.6 \\
\cline { 2 - 4 } & No & 4 & 11.4 \\
\hline \multirow{2}{*}{ Hospital } & Yes & 35 & 100 \\
\cline { 2 - 4 } & No & - & - \\
\multirow{2}{*}{ Library } & Yes & 16 & 45.7 \\
\cline { 2 - 4 } & No & 19 & 54.3 \\
\multirow{2}{*}{ Museum } & Yes & 25 & 71.4 \\
\cline { 2 - 4 } Market Places & No & 32 & 91.4 \\
\cline { 2 - 4 } Theater & Yes & 3 & 8.6 \\
\cline { 2 - 4 } & No & 31 & 88.6 \\
\hline Total & Yes & 35 & 11.4 \\
\cline { 2 - 4 } & No & 100 \\
\hline
\end{tabular}

Analysis of the data presented in Table 3 showed that, the public spaces mentioned in the survey were all experienced by the children. However, looking at the percentage distribution it was observed that $\mathbf{2 . 9} \%$ of the children had never experienced shopping malls, $74.3 \%$ of them had never experienced city halls, $11.4 \%$ of them had never experienced mosques, $54.3 \%$ of them had never experienced libraries, $71.4 \%$ of them had never experienced museums, $8.6 \%$ of them had never experienced market places and $11.4 \%$ had never experienced theaters before. "Hospital" was defined as a public space experienced by all children.

Personal experience is important for the perception of a space's fundamental form and purpose (Heylighen, 2012). Existing images of experienced space are enriched with the body, memory and dreams; thus with the past. In this study, sensory experiences of children in public spaces were aimed to be investigated in terms of the public spaces they interact with. Sensory experiences of children related to public spaces were provided in Table 4 .

Table 4: Frequency and percentage distribution of children's sensory experiences related to public spaces

\begin{tabular}{llll}
\hline Public Spaces & Sensory Experience & f & $\mathbf{0}$ \\
\hline \multirow{3}{*}{ Shopping Mall } & Happy & 29 & 85.3 \\
\cline { 2 - 4 } & Excited & 3 & 8.8 \\
\cline { 2 - 4 } & Exhausted & 1 & 2.9 \\
\cline { 2 - 4 } & Bored & 1 & 2.9 \\
\hline Total & & 34 & $\mathbf{1 0 0}$ \\
\hline City Hall & Happy & 4 & 44.4 \\
\hline
\end{tabular}




\begin{tabular}{|c|c|c|c|}
\hline & Excited & 1 & 11.1 \\
\hline & Entertained & 1 & 11.1 \\
\hline & Curious & 3 & $33 \cdot 3$ \\
\hline Total & & 9 & 100 \\
\hline \multirow{6}{*}{ Mosque } & Happy & 13 & 41.9 \\
\hline & Excited & 4 & 12.9 \\
\hline & Relaxed & 1 & 3.2 \\
\hline & Curious & 2 & 6.5 \\
\hline & Entertained & 3 & 9.7 \\
\hline & Bored & 8 & 25.8 \\
\hline Total & & 31 & 100 \\
\hline \multirow{7}{*}{ Hospital } & Happy & 9 & 25.7 \\
\hline & Excited & 5 & 14.3 \\
\hline & Curious & 2 & $5 \cdot 7$ \\
\hline & Sad & 13 & 37.1 \\
\hline & Exhausted & 2 & $5 \cdot 7$ \\
\hline & Anxious & 3 & 8.6 \\
\hline & Bored & 1 & 2.9 \\
\hline Total & & 35 & 100 \\
\hline \multirow{5}{*}{ Library } & Happy & 7 & 43.8 \\
\hline & Excited & 6 & 37.5 \\
\hline & Entertained & 1 & 6.3 \\
\hline & Sad & 1 & 6.3 \\
\hline & Exhausted & 1 & 6.3 \\
\hline Total & & 16 & 100 \\
\hline \multirow{3}{*}{ Museum } & Happy & 8 & 80 \\
\hline & Excited & 1 & 10 \\
\hline & Bored & 1 & 10 \\
\hline Total & & 10 & 100 \\
\hline \multirow{4}{*}{ Market Places } & Happy & 20 & 62.5 \\
\hline & Excited & 1 & 3.1 \\
\hline & Exhausted & 6 & 18.8 \\
\hline & Bored & 5 & 15.6 \\
\hline Total & & 32 & 100 \\
\hline \multirow{5}{*}{ Theater } & Happy & 24 & 77.4 \\
\hline & Excited & 3 & 9.7 \\
\hline & Entertained & 2 & 6.5 \\
\hline & Sad & 1 & 3.2 \\
\hline & Bored & 1 & 3.2 \\
\hline Total & & 31 & 100 \\
\hline
\end{tabular}

As the moods provided in Table 4 were examined, it was observed that $85.3 \%$ of the children were feeling happy in shopping malls; whereas $8.8 \%$ were excited, $2.9 \%$ were exhausted, and $2.9 \%$ were bored $(\mathrm{N}=34) .44 .4 \%$ of them stated that they were happy in the city hall, whereas $11.1 \%$ reported being excited, $11.1 \%$ being entertained, and 33.3\% being curious $(\mathrm{N}=9) .41 .9 \%$ of the children were happy in the mosque, $\mathbf{1 2 . 9} \%$ were excited, 
3.2\% were relaxed, $6.5 \%$ were curious, $9.7 \%$ were entertained and $25.8 \%$ were bored $(\mathrm{N}=31)$. Whereas $\mathbf{2 5 . 7} \%$ of the children were determined to be happy, $14.3 \%$ excited, $5.7 \%$ curious, $37.1 \%$ sad, $5.7 \%$ exhausted, $8.6 \%$ anxious and $2.9 \%$ to be bored in the hospital $(\mathrm{N}=35)$. It was found that $43.8 \%$ of children were happy, $37.5 \%$ were excited, $6.3 \%$ were entertained, $6.3 \%$ were sad and $6.3 \%$ were exhausted in the library $(\mathrm{N}=16) .80 \%$ of children reported being happy in the museum, while $10 \%$ reported being excited, and $10 \%$ being bored. It was observed that $62.5 \%$ of the children felt happy in the market places, whereas $3.1 \%$ felt excited, $18.8 \%$ exhausted, and $15.6 \%$ bored. On the other hand, $77.4 \%$ of the children stated that they were happy in the theater, while $9.7 \%$ stated being excited, $6.5 \%$ being entertained, $3.2 \%$ being sad and $3.2 \%$ being bored.

These results attained indicate the importance of sensory processes for children in terms of perceiving constructed environments. This can be attributed to the fact that sensory experiences played a major role for the perception of spaces, objects and events, and for helping them constitute a meaningful whole. Children's perception of the cities they reside in, is directly related to their processes of recognizing, experiencing and interpreting that city's public structures.

The metaphors produced about the city were used for revealing out the children's perceptions of the city of Trabzon. These metaphors were analyzed with the content analysis method. Content analysis is a scientific approach that enables the systematic examination of data and its organization based on certain categories (Yıldırım \& Şimşek, 2013). The metaphors produced by the children participating in the research were analyzed and interpreted in four stages.

In the coding and elimination stage, the survey forms were numbered from 1 to 35 and were analyzed based on their including a metaphorical pattern. The forms that wouldn't be evaluated as they did not contain any metaphor, were eliminated $(n=2)$. The metaphors in the remaining 33 forms were listed depending on the frequency they were stated.

"Sample metaphor list" was created in the category development stage for each metaphor, through the sample metaphorical statements considered to be representing in the best way. This list was used as a source of reference in the categorization of metaphors. The metaphors developed by the children were examined in terms of their common characteristics. 5 different conceptual categories were created by gathering interrelated metaphors under the same group.

In the validity and reliability stage, the justifications for the metaphors were directly quoted for validity and the data analysis process was reported in a detailed way. In order to ensure the reliability of the research, the views of two field experts were referred for the metaphors categorized under the conceptual categories. The resulting codes and code-related categories were analyzed by comparing. The approach defined by Miles and Huberman (1994) was used in order to ensure reliability among the coders. According to this approach, when there is a 90\% or more consistency among the codes given by the coders in qualitative researches, the research results are reliable. Agreements 
and disagreements were identified and the reliability among the coders was measured by using $\mathrm{P}$ (Conciliation percentage) $=\mathrm{Na}$ (Agreement) $/ \mathrm{Na}$ (Agreement) $+\mathrm{Nd}$ (Disagreement) $\mathrm{x} 100$ reliability formula. In this research, the average reliability among the coders was found as; $92 \%(33 /(33+3)=92 \%)$. This value shows that the reliability of the research is achieved. 33 metaphors developed by the children about the city of Trabzon are presented in Table 5.

Table 5: The metaphors developed by the children about Trabzon

\begin{tabular}{cccccc}
\hline $\begin{array}{c}\text { Metaphor } \\
\text { Order }\end{array}$ & $\begin{array}{c}\text { Metaphor } \\
\text { Name }\end{array}$ & f & $\begin{array}{c}\text { Metaphor } \\
\text { Order }\end{array}$ & $\begin{array}{c}\text { Metaphor } \\
\text { Name }\end{array}$ & f \\
\hline $\mathbf{1}$ & Playground & 5 & $\mathbf{1 3}$ & Aquarium & $\mathbf{1}$ \\
\hline $\mathbf{2}$ & Painting & 3 & $\mathbf{1 4}$ & School & $\mathbf{1}$ \\
\hline $\mathbf{3}$ & Picture & $\mathbf{2}$ & $\mathbf{1 5}$ & Square & $\mathbf{1}$ \\
\hline $\mathbf{4}$ & Paradise & $\mathbf{2}$ & $\mathbf{1 6}$ & Life & $\mathbf{1}$ \\
\hline $\mathbf{5}$ & Game & $\mathbf{2}$ & $\mathbf{1 7}$ & Athlete & $\mathbf{1}$ \\
\hline $\mathbf{6}$ & Stadium & $\mathbf{2}$ & $\mathbf{1 8}$ & Football & $\mathbf{1}$ \\
\hline $\mathbf{7}$ & Rain & $\mathbf{1}$ & $\mathbf{1 9}$ & Turkey & $\mathbf{1}$ \\
\hline $\mathbf{8}$ & Antalya & $\mathbf{1}$ & $\mathbf{2 0}$ & Ankara & $\mathbf{1}$ \\
\hline $\mathbf{9}$ & Holiday Resort & $\mathbf{1}$ & $\mathbf{2 1}$ & Excursion Spot & $\mathbf{1}$ \\
\hline $\mathbf{1 0}$ & Vessel & $\mathbf{1}$ & $\mathbf{2 2}$ & Center of the & 1 \\
\hline $\mathbf{1 1}$ & Book & $\mathbf{1}$ & $\mathbf{2 3}$ & World & $\mathbf{1}$ \\
\hline $\mathbf{1 2}$ & Straw Bracelet & $\mathbf{1}$ & Total & & $\mathbf{1}$ \\
\hline
\end{tabular}

These metaphors were grouped under five categories as "natural beauty", "variety", "source of fun", "sports activities" and "magnitude". The frequency and percentage distributions regarding the metaphors categorized according to their common characteristics based on their reasons, are given in Table 6. Trabzon

Table 6: Categorical distribution of the metaphors developed by the children about the city of

\begin{tabular}{llcc}
\hline Categories & Metaphors & f & \% \\
\hline Source of fun & Game, playground, square, life & 9 & $\mathbf{2 7 . 2 7}$ \\
\hline Natural beauty & $\begin{array}{l}\text { Picture, rain, painting, paradise, Antalya, holiday } \\
\text { resort }\end{array}$ & 8 & $\mathbf{2 4 . 2 4}$ \\
\hline Variety & $\begin{array}{l}\text { Vessel, painting, book, straw bracelet, aquarium, } \\
\text { school }\end{array}$ & 7 & $\mathbf{2 1 . 2 1}$ \\
\hline $\begin{array}{l}\text { Sports } \\
\text { activities }\end{array}$ & Stadium, athlete, football, Turkey & 5 & $\mathbf{1 5 . 1 5}$ \\
\hline Magnitude & Ankara, excursion spot, center of the World, sea & 4 & $\mathbf{1 2 . 1 2}$ \\
\hline
\end{tabular}

Metaphors developed about the city of Trabzon mostly belonged to the "source of fun" category. This is followed by "natural beauty", "variety", "sports activities" and "magnitude" categories (Table 6). 


\section{1. "Source of Fun" Category}

There are 9 metaphors under this category. These metaphors and frequencies are as "game (2)", "playground (5)", "square (1)" and "life (1)". The children mostly developed metaphors about the "source of fun" category is in parallel with the fact that, the majority of them (62.9\%) preferred playing outside as an out-of-school activity. Some of the metaphorical statements under this category are as follows:

"Trabzon is like a game because it's fun and nice" ( $\left.\mathrm{S}_{7}\right)$.

"Trabzon is like a playground because I have fun when I go out" ( $\left.\mathrm{S}_{5}\right)$.

"Trabzon is like a square because I like wandering around" (S2).

"Trabzon is like life because I like wandering around here" $\left(\mathrm{S}_{3}\right)$.

\section{2. "Natural Beauty" Category}

There are 8 metaphors under this category. These metaphors and frequencies are as "picture (2)", "rain (1)", "painting (1)", "paradise (2)", "Antalya (1)" and "holiday resort (1)". The children identified Trabzon with concepts like picture, paradise and holiday resort to emphasize the city's natural beauty. Some of the metaphorical statements under this category are as follows:

"Trabzon is like a blue-green picture because sea and nature are intertwined" (S16).

"Trabzon is like rain because its forests are always green" (S11).

"Trabzon is like paradise because its nature is very beautiful" (S14).

"Trabzon is like Antalya because it has both forest and sea" ( $\left.\mathrm{S}_{15}\right)$.

"Trabzon is like a holiday resort because it is so nice to walk on the beach and throw stones into the sea" $\left(\mathrm{S}_{17}\right)$.

\section{3. "Variety" Category}

There are 7 metaphors under this category. These metaphors and frequencies are as "vessel (1)", "painting (2)", "book (1)", "straw bracelet (1)", "aquarium (1)" and "school (1)". According to the children, Trabzon is a city with a wide range of variety in terms of its places to visit, historical sites, various types of fish and opportunities to learn new things. Some of the metaphorical statements under this category are as follows:

"Trabzon is like a vessel because it has many places to visit" (S18).

"Trabzon is like a magnificent painting because it has many colors in it" (S19).

"Trabzon is like a book because it has many different beauties" (S21).

"Trabzon is like a straw bracelet because it has lots of historical monuments from ancient times" (S22). 
"Trabzon is like an aquarium because it has many types of fish in it" ( $\left.\mathrm{S}_{23}\right)$.

"Trabzon is like school because we learn new things all the time" (S24).

\section{4. "Sports Activities" Category}

There are 5 metaphors under this category. These metaphors and frequencies are as "stadium (2)", "athlete (1)", "football (1) and Turkey (1)". Trabzon is identified with concepts such as stadium, athlete and football, which shows that the city of Trabzon is considered to be intertwined with sports. Some of the metaphorical statements under this category are as follows:

"Trabzon is like a stadium because I love football and Trabzonspor" (S25).

"Trabzon is like an athlete because it has many sports fields" (S26).

"Trabzon is like football because its athletes are very strong" (S28).

"Trabzon is like Turkey because it has champions" (S29).

\section{5. "Magnitude" Category}

There are 4 metaphors under this category. These metaphors and frequencies are as "Ankara (1)", "excursion spot (1)", "center of the World (1) and "sea (1)". The children described Trabzon as a big and crowded city. Some of the metaphorical statements under this category are as follows:

"Trabzon is like Ankara because it is a big and crowded place" (S30).

"Trabzon is like a big excursion spot because you cannot finish it no matter how much you wander around" (S31).

"Trabzon is like the center of the World because is too big" (S32).

"Trabzon is like sea because it is a big city one can wander around easily" ( $\left.\mathrm{S}_{33}\right)$.

\section{Conclusion}

Architecture constitutes not only the classical five senses, but many fields of sensory experiences that interact and integrate with each other (Pallasmaa, 2012). Within this respect, it is supposed that the metaphors created within the scope of this study would be instructive in terms of perception and interpretation of the environment's morphological and objective features.

The metaphorical statements of the children indicate that they are aware of the natural and built urban environment. Looking at the metaphors it can be stated that, they describe Trabzon as a fun and big city with natural beauties, varieties and sports values. On the other hand, research findings revealed out that certain public spaces haven't been 
experienced by all of the children. The children's perceptions of the city mostly depended on the level of relationship between themselves and the environment. Indeed, the children most perceive the city as a "source of fun", which is in parallel with this. It is natural that the children, who tend to spend their out-of-school time playing outside, describe their environment as a "playground". Once the child socializes by establishing relationship with the environment, he/she begins to realize the built environment. The relationship with the space is shaped by the form of such space and by the user behaviors, whereas the urban space is perceived based on past experiences. In this respect, it is inevitable that the children's perception of space is less developed than that of the adults'.

The activities performed by the children are very important for their development. This is because the spatial behavior of the child does not get shaped based on the physical environment or the quality of the space only. Every part of the daily life enables the children to interact with the space and gain sensual experiences. Due to the limitations of the past experiences of the children, which come to the front in the internalization of the space, spatial perceptions of the children are open to change at all times. Children, just like adults, are directly influenced by their society's everyday life habits, values and the ways of thinking. Thus, the support of the parents and teachers is particularly important in helping the children gain information about the places other than school. Children should be enabled to interact, as much as possible, with the safe and healthy urban spaces. A variety of cultural/artistic activities or sight-observation studies will help the children realize the environment they live in. Excursions, visits or workshops to reveal out the relationship between the children and space, can be planned. Urban spaces can be organized as a place for activities in which small or large groups can observe, dream and generate ideas. Activities like drawing, painting or designing can be used to help the children reveal out their imagination about the environments they have experienced. These methods can help the empowerment of the imagination of the children, their awareness about the spaces they interact with and thus, the improvement of their environmental perceptions.

\section{References}

Bayramoğlu, N. (2010). Urban Identıty in The Context of User's Perception: Barbaros Boulevard-Buyukdere Street Urban Axis (Master Thesis), Istanbul Technical University, Graduate School of Science Engineering and Technology, Istanbul, Turkey.

İnceoğlu, M. \& Aytuğ, A. (2009). The Concept of Urban Space Quality, Megaron, 4 (3): 131-146.

İnceoğlu, M. (2011). Tutum Algı İletişim, Ankara: Siyasal Kitabevi.

Heylighen, A. (2012). Challenging Prevailing Ways of Understanding and Designing Space, In Bhatt, M., Hölscher, C., Shipley, T. (Eds.), Spatial Cognition for Architectural Design SCAD 2011 Symposium Proceedings, 23-40. Bremen/Freiburg: e Transregional Collaborative Research Center SFB/TR 8 Spatial Cognition Universität Bremen / Universität Freiburg.

Kılıçaslan, H. (2010). Creative Drama as an Approach in Design Education (Master Thesis), Karadeniz Technical University, Institute of Natural Sciences, Trabzon, Turkey. 
Lakoff, G. \& Johnson, M. (2003). Metaphors We Live by, USA: The University of Chicago Press.

Miles, M. B. and Huberman, A.M. (1994). Qualitative Data Analysis (2nd edition), Thousand Oaks, California: Sage Publications.

Morgan, G. (1980). Paradigms, Metaphors, and Puzzle Solving in Organization Theory, Administrative Science Quarterly, 25 (4): 605-622.

Özbek, M. (2004). Giriș: Kamusal alanın sınırları, Kamusal Alan, Istanbul, Turkey: Hil Yayınları.

Pallasmaa, J. (2012). The Eyes of the Skin: Architecture and the Senses, England: John Wiley and Sons Ltd.

Yıldırım, A. \& Şimşek, H. (2013). Sosyal Bilimlerde Nitel Araştırma Yöntemleri, Ankara, Turkey: Seçkin Yayınevi. 